\title{
Emulated reactance and resistance by a sssc incorporating energy storage device
}

\author{
H. V. Gururaja Rao ${ }^{1}$, Nagesh Prabhu ${ }^{2}$, R. C. Mala ${ }^{3}$ \\ ${ }^{1,3}$ Department of Electrical and Electronics Engineering, Manipal Institute of Technology, MAHE, India \\ ${ }^{2}$ Department of Electrical and Electronics Engineering, NMAM Institute of Technology, Nitte, India
}

\begin{tabular}{l}
\hline \hline Article Info \\
\hline Article history: \\
Received Jun 9, 2018 \\
Revised Sep 25, 2018 \\
Accepted Oct 19, 2018 \\
\hline
\end{tabular}

\section{Keywords:}

Control strategy

Emulated reactance, resistance

Four quadrant operation

Injected voltage

SSSC with energy storage

\begin{abstract}
Static Synchronous series compensator without energy storage device can exchange only reactive power with the network and can operate in limited operating range in two quadrants only. When energy storage device is connected at the DC bus of SSSC (SSSC - ES), it can also exchange real power with the network. Operating range of SSSC will be much broader and it covers all the four quadrants. However, emulated reactance and resistance by SSSC - ES is likely to affect the performance of a distance protection system. This paper presents a detailed model of an SMIB system with SSSC - ES. Injected voltage by SSSC - ES in all the four quadrants of operation is presented. Impact of operation of SSSC - ES in different quadrants and various control strategies for SSSC - ES on impedance emulated by SSSC - ES during steady state condition and transient system disturbance is discussed.
\end{abstract}

Copyright (C) 2019 Institute of Advanced Engineering and Science. All rights reserved.

\section{Corresponding Author:}

H. V. Gururaja Rao,

Department of Electrical and Electronics Engineering,

Manipal Institute of Technology, MAHE,

Udupi district, Karnataka state, India, Pin: 576104.

Email: gururaj.rao@manipal.edu

\section{INTRODUCTION}

\subsection{Background}

Due to stability constraints, transmission lines are often under-utilized and operated much below their rated capacity. Series connected FACTS controllers help in improving stability margin and hence power transfer capacity of the line [1], [2]. Hybrid series compensation i.e. a passive series capacitor and a SSSC is preferred for economic reasons [3]. In case of VSC based FACTS controllers, there is a provision for connecting energy storage device like battery, fuel cell SMES at the DC bus. This will further improve power transfer through the line [4].

\subsection{Problem and proposed solution}

Operation and control action of FACTS controllers can impact the performance of a power system. Few authors have discussed about the impact of FACTS controllers on the overall power system performance. Performance comparision of SSSC and TCPS in automatic generation control of hydrothermal system is discussed in [5]. In [6], it is shown that response accuracy under system disturbance will improve when PMUs are introduced with FACTS. Modifications in steady state characteristics of a system in case of SSSC with energy storage device is discussed in [7] and STATCOM with energy storage device is discussed in [8]. In [9], STATCOM incorporating a fuel cell is shown to enhance the transient stability of the system. Power oscillation damping controller is designed with STATCOM equipped with energy storage in [10]. Impact of SSSC and UPFC with SMES on distance relay operation is discussed in [11], [12]. Small signal stability analysis of a system with SSSC - ES is highlighted in [13]. Improvement in transient stability of an SMIB system with SSSC is shown in [14]. Bifurcation analysis of SSR with SSSC - ES and 
STATCOM - ES is discussed in [15], [16]. Reactance and resistance emulated by SSSC is likely to affect the operation of distance relay and system stability. Hence, a detailed model and analysis of a system with SSSC - ES is essential to determine the emulated impedance under different operating conditions \& various control strategies for SSSC - ES and study its impact on the system performance. This paper aims to model and study the operation of SSSC in all four quadrants and determine and analyze the emulated impedance by SSSC - ES in different quadrants of operation. The paper will be organized as follows. Detailed system model and governing equations can be found in Section 2. Methodology followed is covered in Section 3. Section 4 presents and analyses the results obtained. Inference drawn from the studies carried out is highlighted in Section 5.

\section{SYSTEM MODEL}

Figure 1 shows the hybrid series compensated SMIB system. Here ' $\mathrm{Xt}$ ' is the reactance of transformer, $(\mathrm{RL}+\mathrm{j} \mathrm{XL})$ is the net impedance of the line ' $\mathrm{Xc}$ ' is the capacitive reactance of series capacitor and 'Xsys' is the system reactance on the infinite bus side. 'Eb' is the infinite bus voltage.

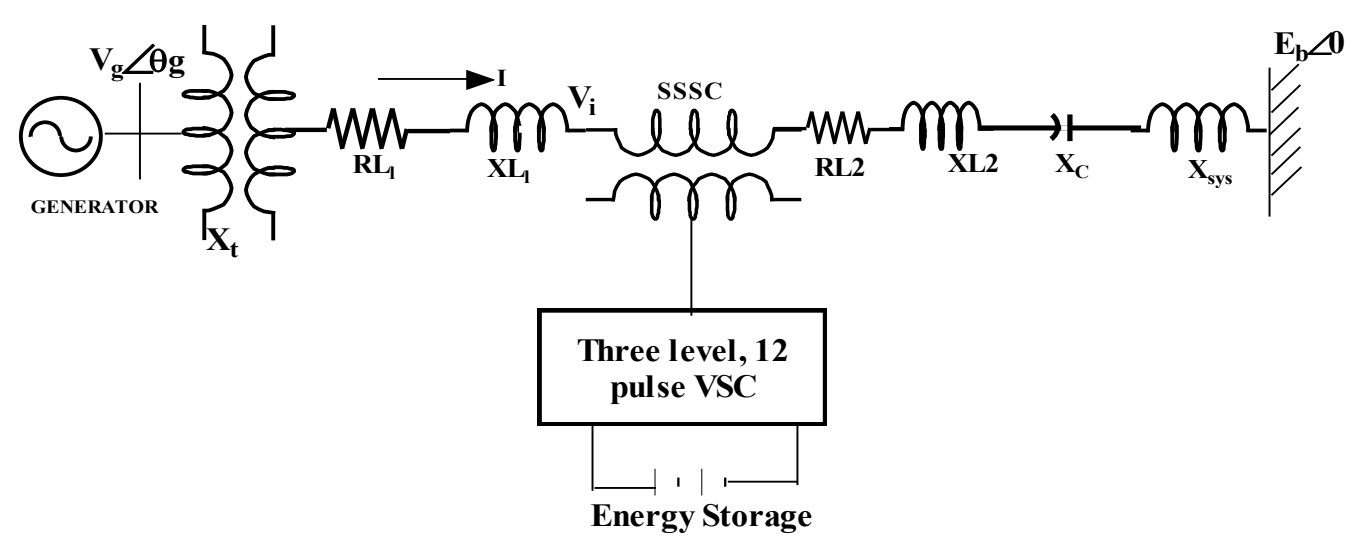

Figure 1. Hybrid series compensated System

\subsection{System equations}

System is modeled in DQ frame of reference. Injected voltage by SSSC - ES is given by

$V^{i}=\sqrt{V_{Q}^{i^{2}}+V_{D}^{i^{2}}}$

where,

$$
\begin{gathered}
V_{D}^{i}=K_{m} * V_{d c} * \operatorname{Sin}(\Phi+\gamma) \\
V_{Q}^{i}=K_{m} * V_{d c} * \operatorname{Cos}(\Phi+\gamma)
\end{gathered}
$$

Where $\mathrm{K}_{\mathrm{m}}=\mathrm{K}^{*} \rho_{\mathrm{se}} *{ }_{\cos } \beta ; \mathrm{K}=\frac{2 \sqrt{6}}{\pi}$ for a 12 pulse converter, ' $\rho_{\mathrm{se}}$ ' is the turns ratio of the transformer and

$$
\Phi=\tan ^{-1}\left(\frac{i_{D}}{i_{Q}}\right)
$$

For better analysis, real (in phase) and reactive (quadrature) components of SSSC - ES can be used, described by:

$$
\begin{aligned}
& V_{P}=V_{D}^{i} \operatorname{Sin} \Phi+V_{Q}^{i} \operatorname{Cos} \Phi \\
& V_{R}=V_{D}^{i} \operatorname{Cos} \Phi-V_{Q}^{i} \operatorname{Sin} \Phi
\end{aligned}
$$


It should be noted that a positive value of $\mathrm{V}_{\mathrm{P}}$ signifies SSSC- ES drawing active power and negative value indicates SSSC - ES supplying power. Similarly, negative value of $V_{R}$ indicates capacitive mode and positive $V_{R}$ implies inductive mode of operation of SSSC - ES.

Equations (7) and (8) are used to calculate ' $\gamma$ 'and ' $\beta$ '.

$$
\begin{aligned}
& \gamma=\tan ^{-1}\left(\frac{V_{R(\text { ord })}}{V_{P(\text { ord })}}\right) \\
& \beta=\operatorname{Cos}^{-1}\left(\frac{\sqrt{V_{P(o r d)}^{2}+V_{R(o r d)}^{2}}}{k * \rho_{s e} e^{*} d c}\right)
\end{aligned}
$$

Equations (9) to (15) are the governing equations for the system shown in Figure 1.

$$
\begin{aligned}
& \text { Line current I }=\sqrt{i_{Q}^{2}+i_{D}^{2}} \\
& \frac{d i_{Q}}{d t}=\frac{W_{b}}{X_{l}}\left[V_{g Q}-E_{b Q}-i_{Q} R_{l}+X_{l} i_{D}-V_{Q}^{i}-V_{c Q}\right] \\
& \frac{d i_{D}}{d t}=\frac{W_{b}}{X_{l}}\left[V_{g D}-E_{b D}-i_{D} R_{l}-X_{l} i_{Q}-V_{D}^{i}-V_{c D}\right]
\end{aligned}
$$

Voltage at the generator bus and the power generated by the generator are described by (12) and (13).

$$
\begin{aligned}
& V_{g m}=\sqrt{V_{g Q}^{2}+V_{g D}^{2}} \\
& P_{g}=V_{g Q} * i_{Q}+V_{g D} * i_{D}
\end{aligned}
$$

Equations (14) and (15) represent expressions for $V_{R}$ and active power component of SSSC -ES respectively.

$$
\begin{gathered}
-\left(X_{S S S C} * I\right)=V_{D}^{i} * \operatorname{Cos} \varphi-V_{Q}^{i} * \operatorname{Sin} \varphi \\
P=i_{D} * V_{D}^{i}+i_{Q} * V_{Q}^{i}
\end{gathered}
$$

\subsection{Control strategy}

In case of SSSC- ES, type 1 control is generally used in order to control both the magnitude and phase angle of the converter output voltage. Real and reactive voltages, $\mathrm{V}_{\mathrm{P} \text { (ord) }}$ and $\mathrm{V}_{\mathrm{R} \text { (ord) }}$ are used to calculate phase angle ' $\gamma$ ' and dead angle ' $\beta$ ' using Equations (7) and (8). Various control strategies proposed are:

a. Real power controller, emulated resistance controller and constant real voltage control.

b. Emulated reactance controller and constant reactive voltage control.

Figure 2 explains the control strategy used.

Eigen value analysis is done to analyze the stability of the system under different operating conditions of SSSC- ES. PI controller values are selected based on root locus design and transient analysis [13]. 


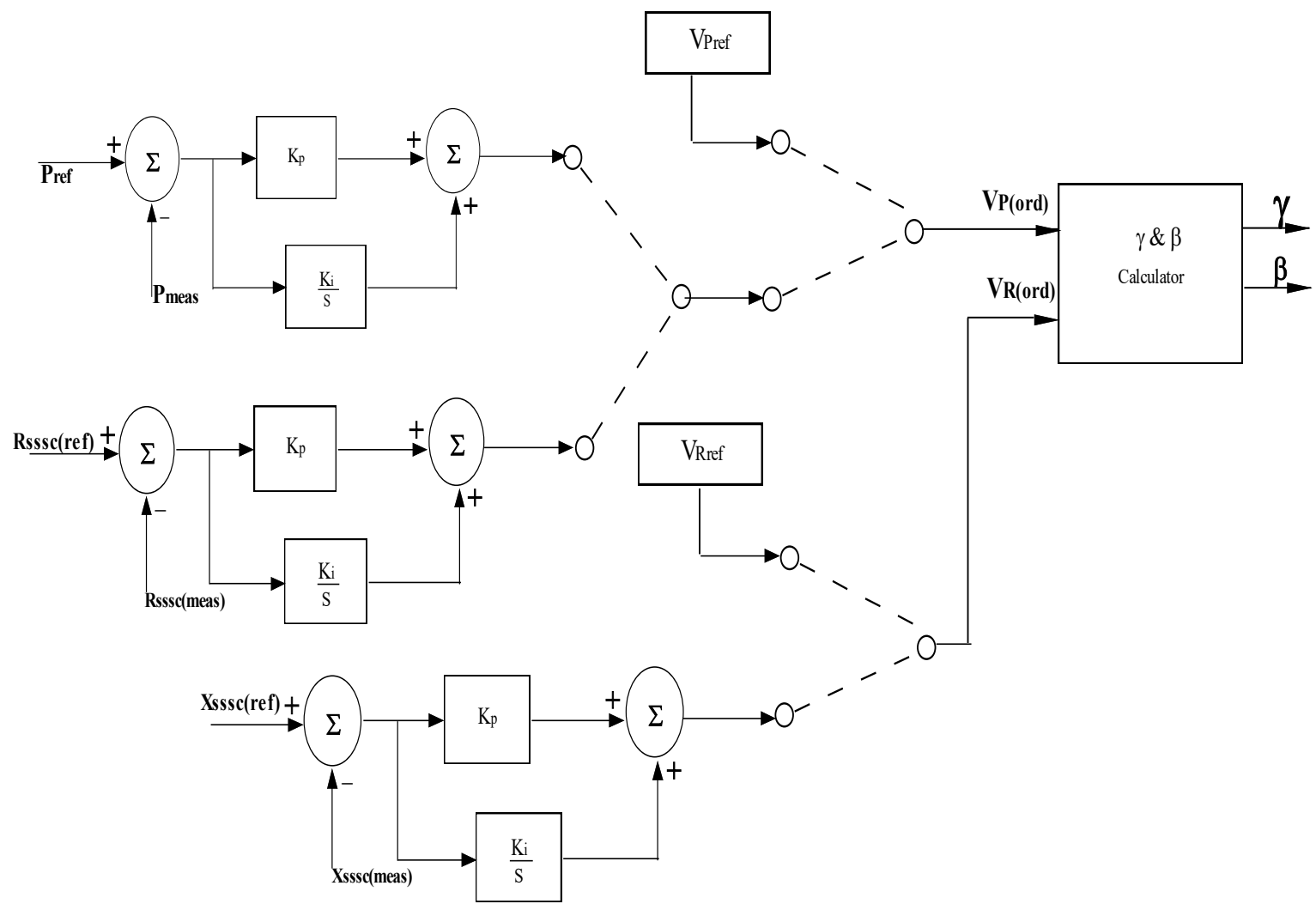

Figure 2. Control strategy for SSSC- ES

\section{METHODOLOGY}

System shown in Figure 1 is modeled in Matlab/Simulink. Newton Raphson iterative method is used to obtain the initial conditions. Generator output power $(\mathrm{Pg})$ is taken as $0.9 \mathrm{pu}$. DC bus voltage of SSSC - ES is assumed to be maintained constant by the energy storage device at $0.7 \mathrm{pu}$.

\subsection{Operating range of SSSC - ES}

A 150 MVA SSSC - ES is used in the present work. With a base MVA of 892.4MVA and with a line current of $1 \mathrm{pu}$, SSSC can inject a voltage (magnitude) of $0.16809 \mathrm{pu}$. Considering a reactance compensation of $45 \%$ from passive series capacitor and a net reactance compensation range of $30 \%$ to $60 \%$, SSSC reactance can be varied between - $0.15 \mathrm{pu}$ (capacitive) and $0.15 \mathrm{pu}$ (inductive). Real and reactive values of injected voltages were determined through simulation for various values of real power exchange by SSSC - ES and from the values obtained, real power exchange by SSSC- ES is limited between - 0.08pu and $0.08 \mathrm{pu}$ when Xsssc value is $\pm 0.15 \mathrm{pu}$. Whereas with SSSC injecting real voltage alone (Xsssc $=0$ ), real power exchange can be up to $0.15 \mathrm{pu}$.

\subsection{Computation of impedance}

Equations 16 to 18 are used to determine the impedance values analytically and are validated through simulation.

Impedance emulated by SSSC,

$$
Z_{S S S C}=R_{S S S C}+j X_{S S S C}=\frac{V^{i}}{I}
$$

Where, $R_{S S S C}=\frac{V_{P}}{I}$ and $X_{S S S C}=\frac{V_{R}}{I}$

Impedance between generator and infinite bus,

$$
Z_{G I B}=Z_{\text {line }}+Z_{S S S C}-j X_{C}+j X_{t}+j X_{S y s}
$$




\section{RESULTS AND DISCUSSION}

\subsection{Injected voltage}

With out energy storage device at the DC bus, injected voltage by SSSC with respect to line current will be close to $\pm 90^{\circ}$. When an energy storage device is connected at the DC bus, angle of injected voltage can be anay angle between $0^{\circ}$ and $360^{\circ}$ or $-180^{\circ}$ and $+180^{\circ}$. Voltage injected by SSSC - ES in different quadrants of operation with respect to line current obtained through simulation is discussed in this section.

\subsubsection{Reactive voltage injection}

When SSSC - ES injects only reactive voltage (Reactive power exchange), injected voltage should be in quadrature with the line current (lagging by $90^{\circ}$ in case of capacitive mode and leading by $90^{\circ}$ in case of inductive mode. Simulation results obtained (Figure 3 and Figure 4) clearly validate this.

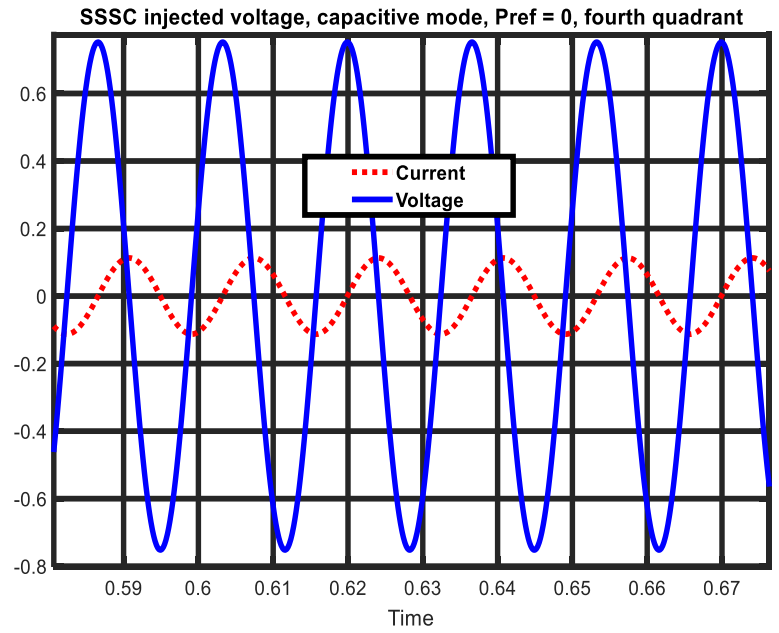

Figure 3. Capacitive reactance compensation, $\gamma=-90^{\circ}$

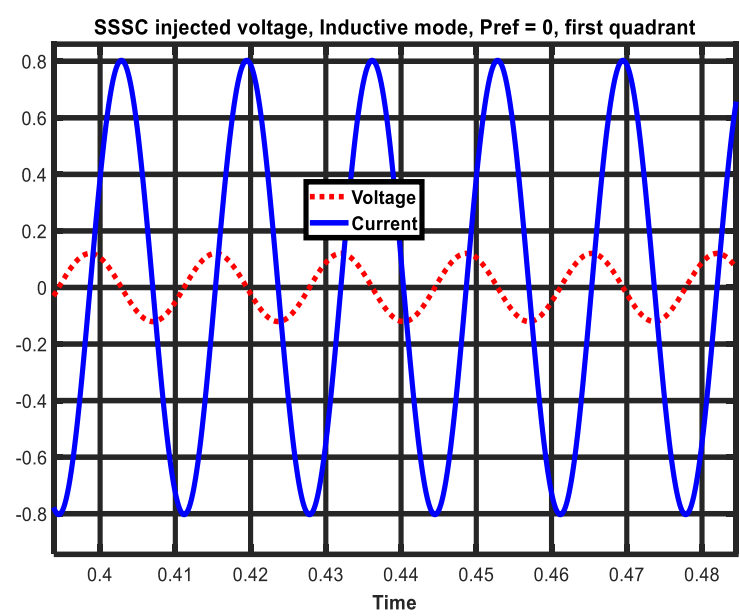

Figure 4. Inductive reactance compensation,

$$
\gamma=90^{\circ}
$$

\subsubsection{Real voltage injection}

When SSSC - ES exchanges real power alone (injects real voltage), injected voltage should be in phase with current while absorbing power and anti-phase while supplying power. Figure 5 and Figure 6 show the injected voltage under these operating conditions.

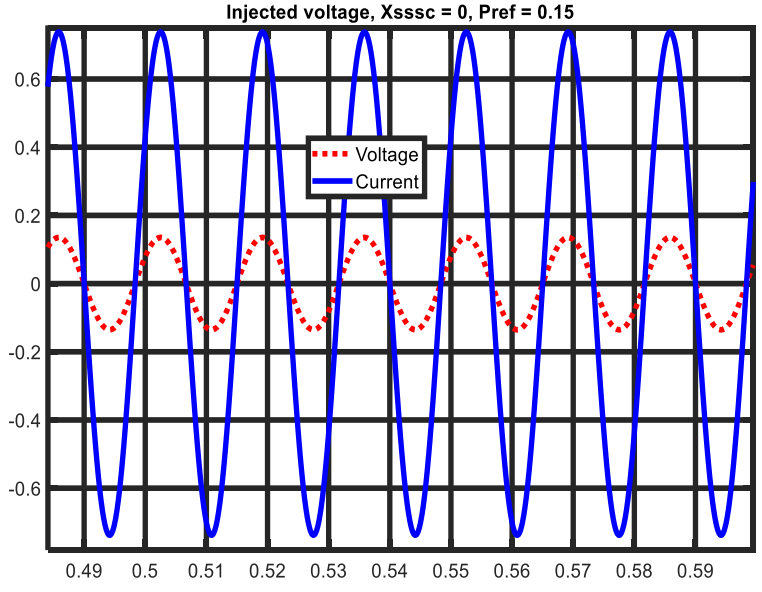

Figure 5. SSSC absorbing Real power, $\gamma=0^{\circ}$

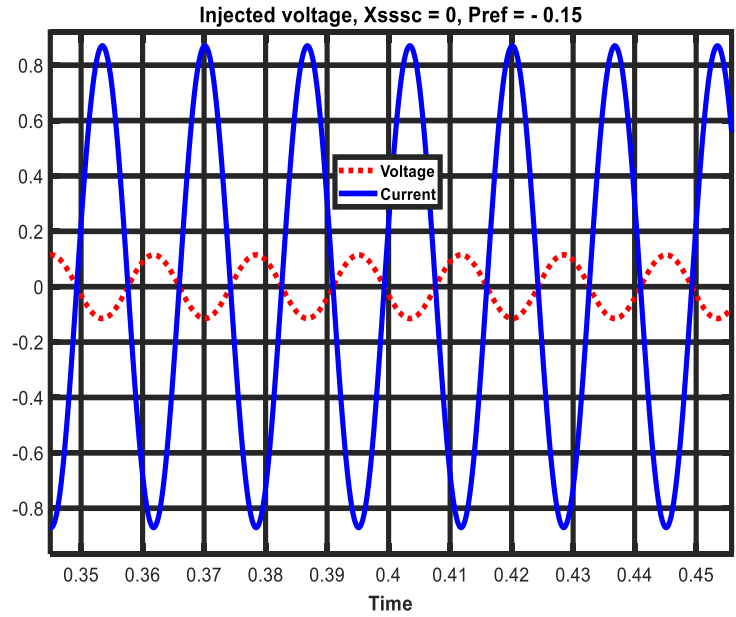

Figure 6. SSSC supplying real power, $\gamma=180^{\circ}$ 


\subsubsection{Simultaneous real and reactive voltage injection}

When SSSC - ES injects both real and reactive power, angle of SSSC injected voltage depends on the operating condition i.e. quadrant of operation. As shown in Figure 7, operation will be in $4^{\text {th }}$ quadrant when SSSC is in capacitive mode and is drawing real power ( $V_{P}$ is positive and $V_{R}$ is negative). Similarly with SSSC in capacitive mode and is supplying real power, operation will be in $3^{\text {rd }}$ quadrant $\left(V_{P}\right.$ is negative and $V_{R}$ is negative) as evident from Figure 8.

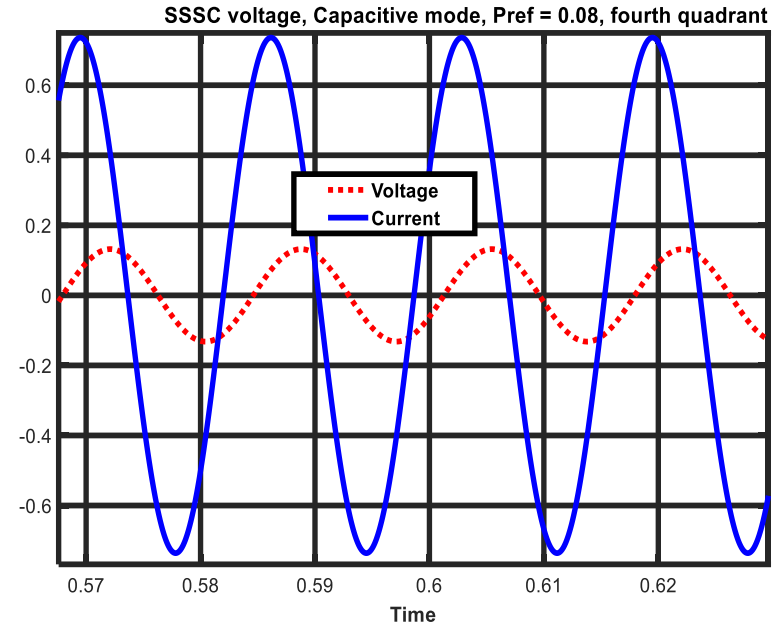

Figure 7. Operation in fourth quadrant, $\mathrm{Gamma}=-56.72^{\circ}$

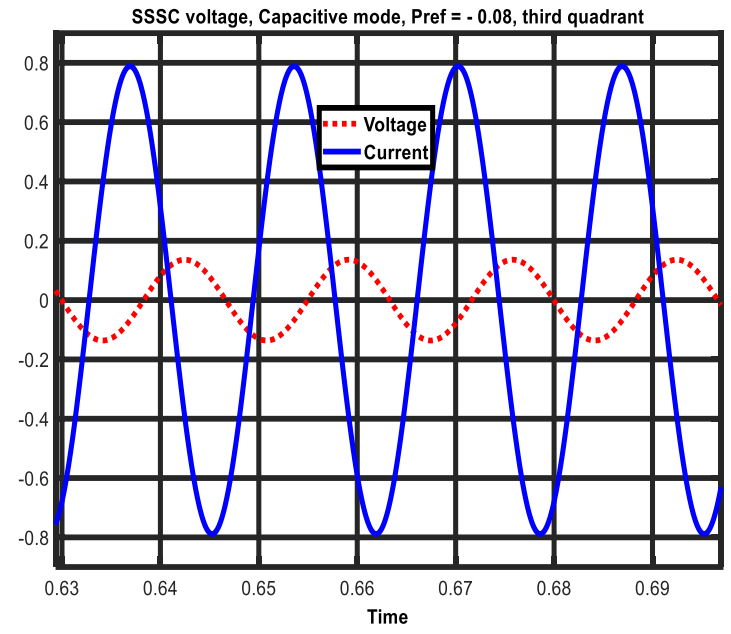

Figure 8. Operation in third quadrant, $\mathrm{Gamma}=-119.8^{\circ}$

When SSSC is in inductive mode, operation will be in first ( SSSC absorbing power) or second ( SSSC supplying power) quadrant. The result obtained through simulation are shown in Figure 9 and Figure 10.

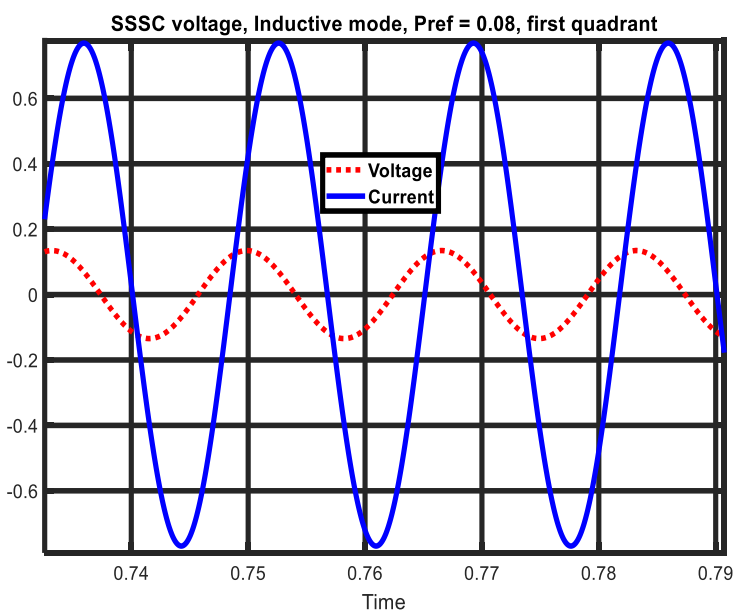

Figure 9. Operation in first quadrant, Gamma $=58.98^{\circ}$

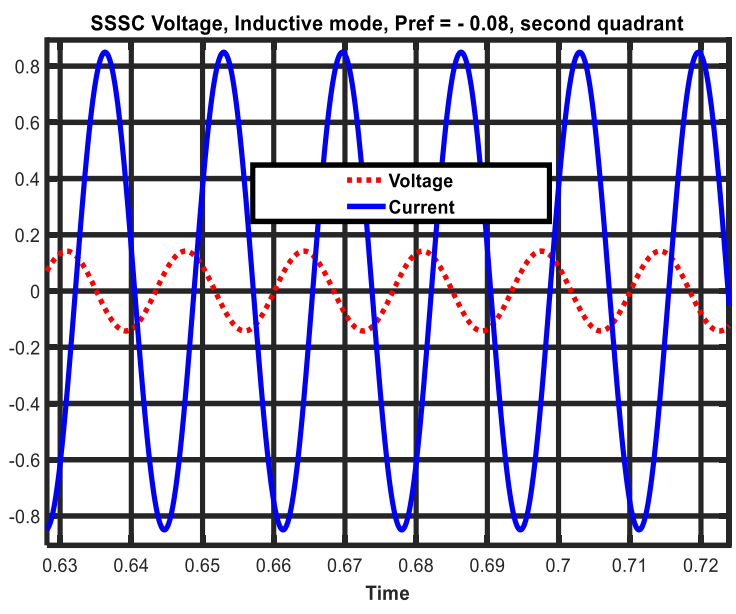

Figure 10. Operation in second quadrant, $\mathrm{Gamma}=116.2^{\circ}$

\subsection{Emulated impedance by SSSC - ES}

Distance protection is the preferred protection for long transmission lines. Operation of distance relay is based on the apparent impedance measured by the relay. Impedance emulated by SSSC - ES will change the measured impedance by the relay and hence the relay may mal operate. When SSSC - ES is injecting reactive voltage alone, it will emulate and change reactance component of impedance. 
Similarly while injecting real voltage alone, it should emulate and change resistance component of impedance. Obviously, when SSSC - ES exchanges both real and reactive power, it will emulate and change both real and imaginary part of impedance. Table 1 gives the results obtained through simulation. From table 1 it is clear that impedance emulated by SSSC - ES depends on the Operating condition i.e. quadrant of operation. It can be noted that in capacitive mode of operation, SSSC emulates negative reactance and hence net reactance reduces, while net reactance increases in case of inductive mode due to positive reactance emulation. Similarly, net resistance increases due to positive resistance emulation when SSSC absorbs power and decreases when SSSC supplies power due to negative resistance emulation. Impedance values are determined analytically using Equations 16 to 18 . System data for impedance computation are $Z_{\mathrm{L}}=0.04+\mathrm{j} 1 ; \mathrm{X}_{\mathrm{SYS}}=$ $\mathrm{j} 0.06, \mathrm{XC}=-\mathrm{j} 0.45, \mathrm{Xt}=\mathrm{j} 0.14$; all values in pu. For a given operating condition, $\mathrm{Vp}, \mathrm{VR}$ and line current values are obtained through simulation.

From Table 1, it can also be noted that impedance values determined through simulation matches with the corresponding values obtained analytically.

Table 1. Steady State Impedance under Various Operating Conditions of SSSC - ES

\begin{tabular}{cccc}
\hline Operating condition & $\mathrm{Z}_{\mathrm{GIB}}($ Analytical $)$ & $\mathrm{Z}_{\mathrm{GIB}}($ measured $)$ & $\mathrm{Z}_{\mathrm{SSSC}}$ \\
\hline No SSSC & $0.04+\mathrm{j} 0.75$ & $0.0399+\mathrm{j} 0.75$ & $0+\mathrm{j} 0$ \\
$\mathrm{Xsssc}=-0.15$, Pref $=0$ & $0.04+\mathrm{j} 0.6$ & $0.0399+\mathrm{j} 0.6$ & $0-\mathrm{j} 0.15$ \\
$\mathrm{Xsssc}=-0.15$, Pref $=0.08$ & $0.1384+\mathrm{j} 0.6$ & $0.13847+\mathrm{j} 0.6$ & $0.098475-\mathrm{j} 0.15$ \\
$\mathrm{Xsssc}=-0.15$, Pref $=-0.08$ & $-0.045+\mathrm{j} 0.6$ & $-0.0457+\mathrm{j} 0.6$ & $-0.085786-\mathrm{j} 0.15$ \\
$\mathrm{Xsssc}=-0.15$, Pref $=0$ & $0.04+0 \mathrm{j} .9$ & $0.0399+\mathrm{j} 0.9$ & $0+\mathrm{j} 0.15$ \\
$\mathrm{Xsssc}=0.15$, Pref $=0.08$ & $0.13+\mathrm{j} 0.9$ & $0.1302+\mathrm{j} 0.9$ & $0.090205+\mathrm{j} 0.15$ \\
$\mathrm{Xsssc}=0.15$, Pref $=-0.08$ & $-0.034+\mathrm{j} 0.9$ & $-0.033943+\mathrm{j} 0.9$ & $-0.073939+\mathrm{j} 0.15$ \\
$\mathrm{Xsssc}=0$, Pref $=0.15$ & $0.224+\mathrm{j} 0.75$ & $0.22426+\mathrm{j} 0.75$ & $0.18427+\mathrm{j} 0$ \\
$\mathrm{Xsssc}=0$, Pref $=-0.15$ & $-0.097+\mathrm{j} 0.75$ & $-0.096985+\mathrm{j} 0.75$ & $-0.13698+\mathrm{j} 0$ \\
\hline
\end{tabular}

Values in Table 1 were obtained through simulation with constant $\mathrm{P}$ control for real voltage and constant reactive voltage control. How ever simulation results with different combinations of control strategy for real and reactive voltage of SSSC - ES showed that for a given operating condition, without any system disturbance, impedance emulated by SSSC - ES is independent of control strategy used. Table 2 shows the simulation result for one of the operating condition ( Xsssc $=-0.15$, Pref $=0.08$, operation in fourth quadrant).

Table 2. Steady State Impedance with Various Control Strategies of SSSC - ES

\begin{tabular}{ccccc}
\hline Operating condition & Control strategy & $Z_{\text {Sssc }}$ (analytical) & \multicolumn{2}{c}{$Z_{\text {Sssc }}($ measured) } \\
\hline Xsssc $=-0.15$, Pref $=0.08$ & Constant P, Vr & $0.09847-\mathrm{j} 0.15$ & $0.098474-\mathrm{j} 0.15$ \\
Xsssc $=-0.15$, Pref $=0.08$ & Constant P, Xsssc & $0.09847-\mathrm{j} 0.15$ & $0.098474-\mathrm{j}$ & 0.15 \\
Xsssc $=-0.15$, Pref $=0.08$ & Constant Vp, Vr & $0.09847-\mathrm{j} 0.15$ & $0.098474-\mathrm{j}$ & 0.15 \\
Xsssc $=-0.15$, Pref $=0.08$ & Constant Vp, Xsssc & $0.09847-\mathrm{j} 0.15$ & $0.098474-\mathrm{j} 0.15$ \\
Xsssc $=-0.15$, Pref $=0.08$ & Constant Rsssc, Vr & $0.09847-\mathrm{j} 0.15$ & $0.098474-\mathrm{j} 0.15$ \\
Xsssc $=-0.15$, Pref $=0.08$ & Constant Rsssc, Xsssc & $0.09847-\mathrm{j} 0.15$ & $0.098474-\mathrm{j}$ & 0.15
\end{tabular}

\subsection{Effect of control strategy on emulated impedance, during system disturbance}

During any transient system disturbance line current is expected to change. Hence emulated impedance by SSSC - ES during disturbance is expected to be different with various control strategies. In order to analyze the effect of control strategy used for SSSC, during transient condition, a step change in mechanical torque input to generator $(\mathrm{Tm})$ is considered. Tm is changed from $0.9 \mathrm{pu}$ to $1.1 \mathrm{pu}$ at 1.5 second for a duration of $0.1 \mathrm{sec}$. Due to increase in mechanical torque input, there will be an increase in line current value during disturbance. Resistance, reactance and impedance emulated by SSSC - ES during such a disturbance, with various control strategies proposed and different operating conditions are determined through simulation.

\subsubsection{Emulated reactance}

Operation of a reactance relay depends on the apparent reactance measured by the relay. Reactance emulated by SSSC depends mainly on the reactive voltage injected by SSSC and line current. For the following operating conditions of SSSC - ES reactance emulated by SSSC is obtained through simulation, employing the proposed control strategies.

Case 1: Operation in fourth quadrant; capacitive mode, no real power.

Case 2: Operation in first quadrant; Inductive mode, no real power 
Plots of reactance emulated by SSSC - ES under these operating conditions is shown in Figure 11 and 12 respectively. It can be noted from Figure 11 that SSSC - ES emulates a negative reactance in capacitive mode of operation and it emulates a positive reactance in inductive mode of operation as shown in Figure12.

It is also very clear from Figure 11 and 12 that reactance emulated by SSSC remains almost constant, before, during and after the disturbance with constant Xsssc control. This however would require an increase in injected voltage by SSSC during disturbance (due to increased current). In case of constant reactive voltage control, Figure 11 and 12 clearly show that the emulated reactance by SSSC - ES is reduced during disturbance due to increase in current magnitude.

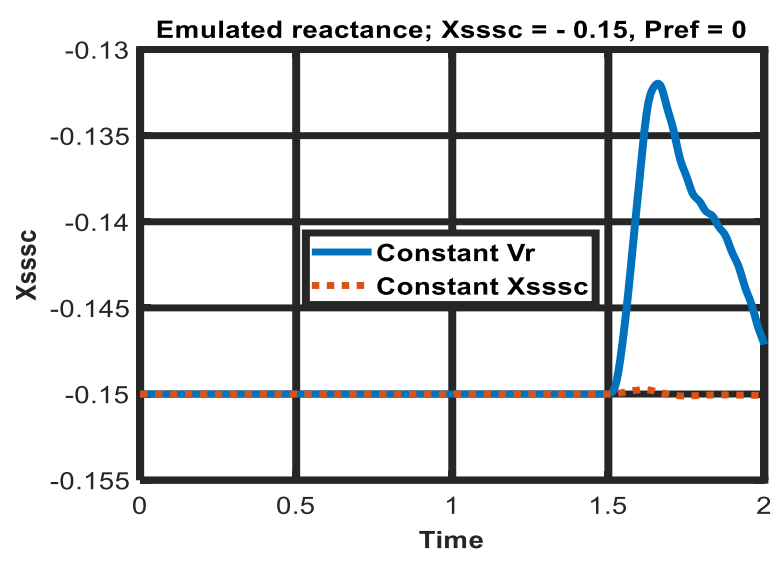

Figure 11. Emulated reactance by SSSC, capacitive mode

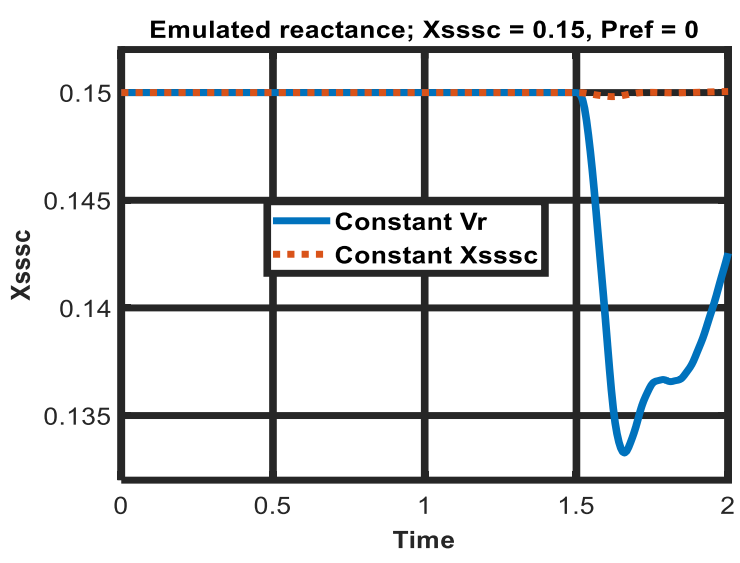

Figure 12. Emulated reactance by SSSC, inductive mode

\subsubsection{Emulated resistance}

Resistance emulated by SSSC depends on the real voltage injected by SSSC and line current. For the following operating conditions, resistance emulated by SSSC was computed employing the proposed control strategies.

Case 3: Operation in first quadrant; No reactive power exchange, absorbing real power

Case 4: Operation in second quadrant; No reactive power, supplying real power

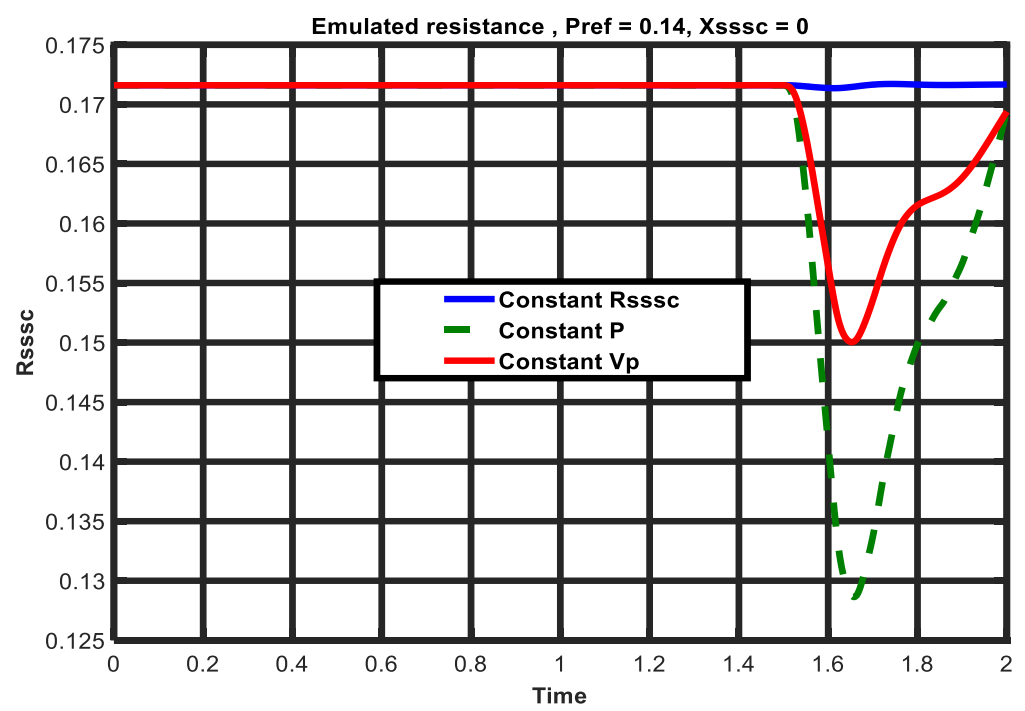

Figure 13. Emulated resisance by SSSC 


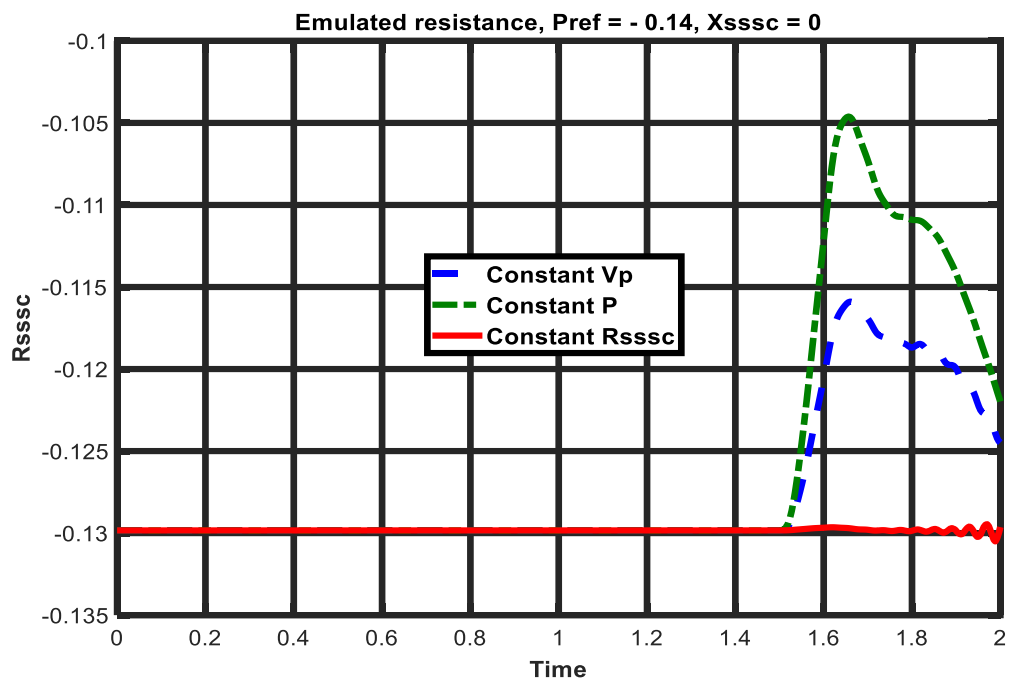

Figure 14. Emulated resistance by SSSC, supplying power

Figure 13 and Figure 14 show the plot of emulated resistance under these conditions. It can be noted from Figure 13 that since SSSC - ES is absorbing power it emulates positive resistance. Also resistance emulated by SSSC remains almost constant, before, during and after the disturbance with constant Rsssc control. This however calls for increase in injected voltage by SSSC during disturbance (Since current is increased during disturbance). It is further observed that positive resistance emulated by SSSC - ES is decreased during disturbance with constant $\mathrm{P}$ control and constant $\mathrm{Vp}$, due to increase in current. Variation is more in case of constant $\mathrm{P}$ control since $\mathrm{Vp}$ will decrease with increase in current, to maintain ' $\mathrm{P}$ ' constant.

It is very clear from Figure 14 that since SSSC - ES is supplying power it emulates negative resistance. It is further observed that emulated resistance remains constant during and after disturbance with constant $\mathrm{R}_{\mathrm{SSSC}}$ control whereas with constant real voltage and constant real power control, magnitude of the emulated resistance is decreased during disturbance due to increase in current.

\subsubsection{Emulated impedance}

Variation in emulated resistance and reactance values during system disturbance with various control strategies and different operating conditions of SSSC - ES were discussed separately in the previous section. Operation of an impedance relay or a mho relay is based on the magnitude of the apparent impedance measured by the relay. In order to analyze the impact of control strategy employed on emulated impedance, following operating conditions were considered.

Case 5: Capacitive mode absorbing power $(\mathrm{Xsssc}=-0.15$, Pref $=0.08)$

i. Constant Vp, Vr control

ii. Constant Rsssc, Xsssc control.

Case 6: Inductive mode absorbing power $(\mathrm{Xsssc}=0.15$, Pref $=0.08)$

i. Constant Vp, Vr control

ii. Constant Rsssc, Xsssc control.

Plot of emulated impedance under these operating conditions shown in Figure 15 and Figure 16. It is interesting to note that with constant Rsssc and constant Xsssc control, variation in magnitude of emulated impedance by SSSC - ES during and after disturbance is negligible. In case of constant injected voltage control, there is significant change in emulated impedance by SSC - ES. 


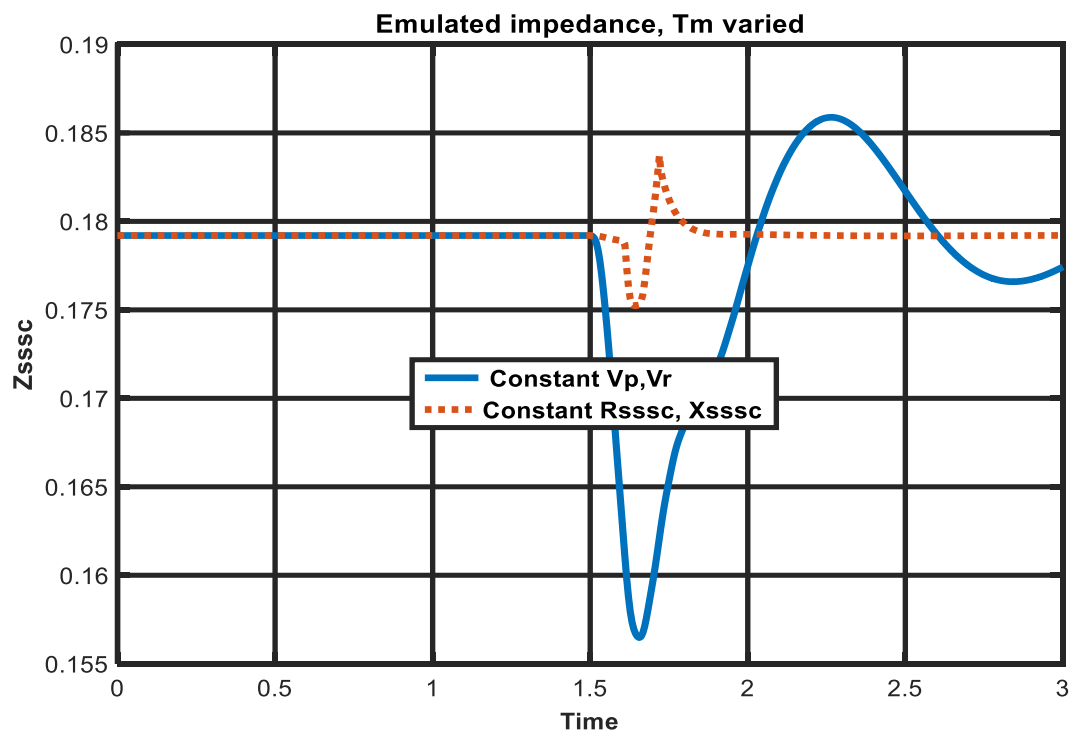

Figure 15. Emulated impedance by SSSC, capacitive mode absorbing power

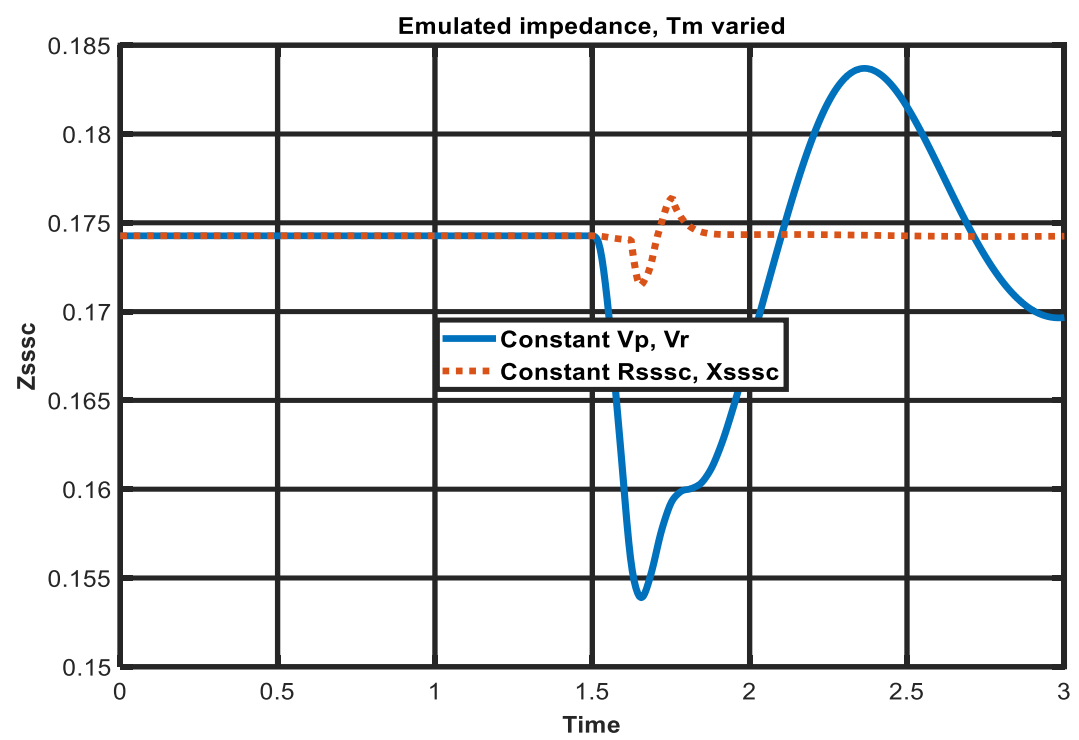

Figure 16. Emulated impedance by SSSC, inductive mode absorbing power

\subsection{Discussion}

The inferences from the analysis of 4 quadrant operation of SSSC are

a. When SSSC injects reactive voltage alone, injected voltage will be $+/-90^{\circ}$ with respect to line current.

b. When SSSC injects both real and reactive voltage, it can operate in all the four quadrants and injected voltage will be between $+180^{\circ}$ and $-180^{\circ}$ with respect to line current.

c. Impedance emulated by SSSC depends on the operating condition.

d. In steady state, impedance emulated by SSSC for a given operating condition is independent of control strategy used for SSSC - ES.

e. During a transient system disturbance, control strategy used for SSSC - ES will have significant impact on the reactance and resistance emulated by SSSC.

f. Constant Rsssc and Xsssc control strategy will maintain the resistance and reactance emulated by SSSC almost constant during and after disturbance.

g. Emulated impedance offered by SSSC - ES significantly changes during system disturbance, for constant injected voltage control strategy and constant real power control. 
h. Variation in reactance and resistance emulated by SSSC - ES during various operating conditions and control strategies of SSSC - ES is likely to modify the apparent impedance measured at the relay location. This can cause mal operation of the distance relay.

\section{CONCLUSION}

In this paper detailed modeling of an SMIB system with SSSC - ES is presented. Operation of SSSC in all the 4 quadrants and injected voltage by SSSC with respect to line current is discussed. Emulated reactance and resistance by SSSC - ES during various operating conditions is determined analytically and validated through simulation. It is shown that operating condition of SSSC - ES will influence the emulated reactance and resistance. It is further shown that during a system disturbance, the emulated impedance by SSSC - ES depends on the control strategy adopted. Impedance values determined analytically under various operating conditions of SSSC - ES are validated through simulation results. Variation in emulated reactance and resistance by SSSC -ES during system disturbance will have an impact on the operation of a distance relay. The apparent impedance seen by the relay will get modified and is likely to cause mal operation of distance relay.

\section{REFERENCES}

[1] K.R. Padiyar, FACTS controllers in Power transmission and Distribution, New Age International, 2008.

[2] N.G.Hingorani and L.Gyugyi, Understanding FACTS. New York: IEEE press, 2000.

[3] K.R. Padiyar and Nagesh Prabhu, "Analysis of sub synchronous resonance with three level twelve pulse VSC based SSSC," in proc, IEEE TENCON - 2003, October 14 - 17, 2003.

[4] L. Zhang, C. Shen, M.L. Crow, S Atcitty, "A comparision of FACTS integrated with battery energy storage systems", IEEE PES transmission and distribution conference, USA, 2001.

[5] K. Subbaramaiah, V.C. Jagan Mohan, V.C. Veera reddy, "Comparision of performance of SSSC and TCPS in automatic generation control of hydrothermal system under deregulated scenario," International journal of Electrical and Computer Engineering (IJECE), vol. 1, no. 1, pp. 21 -30, September 2011.

[6] Hussain I Hussein, Ghassan Salman, M.S. Hassan, "Phase measurement units based FACTS devices for the improvement of power system networks controllability," International journal of Electrical and Computer Engineering (IJECE), vol. 8, no. 2, pp. 888-899, April 2018.

[7] L. Zhang, M.L. Crow, Z. Yang, S. Chen, "The steady state characteristics of an SSSC integrated with energy storage," in proc. Power engineering society winter meeting, vol. 3, IEEE 2001.

[8] Z. Yang, M.L. Crow, C. Shen, L. Zhang, "The steady state characteristics of a STATCOM with energy storage," in proc. Power engineering society summer meeting, vol. 2, IEEE 2000.

[9] M. Stella, Morris A.G. Ezra, A. Peer Fathima, C. Khang Jiunn, "Research on the efficacy of unified STATCOMFuel cells in improving the transient stability of power systems," International Journal of hydrogen energy, 2016.

[10] Mebtu Beza, Massimo Bongiorno, "An adaptive Power Oscillation Damping Controller by STATCOM with Energy Storage,” IEEE Trans. Power Sys., pp. 484-493, Jan. 2015.

[11] A. Kazemi, S. Jamali and H. Shateri, "Effects of SMES Equipped SSSC on Distance Relay Tripping Characteristic," Transmission and Distribution Conference and Exposition, 2008, IEEE/PES, April 2008.

[12] Jamali, A. Kazemi and H. Shateri, "Effect of SMES Equipped UPFC on Distance Relay Tripping Characteristic," Power System Technology and IEEE Power India Conference, 2008. POWERCON 2008.

[13] H.V. Gururaja Rao, Nagesh Prabhu, R.C. Mala, "Investigations on stability of a hybrid series compensated system with SSSC-ES," IEEE International Conference on Technological Advancements in Power and Energy (TAPEnergy2015), Amrita School of Engineering, Kollam, June 24 - 262015.

[14] Md. Imran Azim, Md. Abdul Wahed, Md. Ahsanul Haque Chowdhury, "Influencing Power Flow and Transient Stability by Static Synchronous Series Compensator," Indonesian Journal of Electrical Engineering and Informatics, vol. 3, no. 2, pp. 63-69, June 2015.

[15] R.C. Mala, Nagesh Prabhu, H.V. Gururaja Rao, "Hopf Bifurcations of Subsynchronous Resonance in a Hybrid Series Compensated System with SSSC-ES," IEEE International Conference on Technological Advancements in Power and Energy (TAPEnergy2015), Amrita School of Engineering, Kollam, June 24 - 262015.

[16] R.C. Mala, Nagesh Prabhu, H.V. Gururaja Rao, "Performance of STATCOM - ES in mitigating SSR," International Journal of Power Electronics and Drive Systems (IJPEDS), vol. 8, no. 4, pp. 1822 -1829, December 2017. 